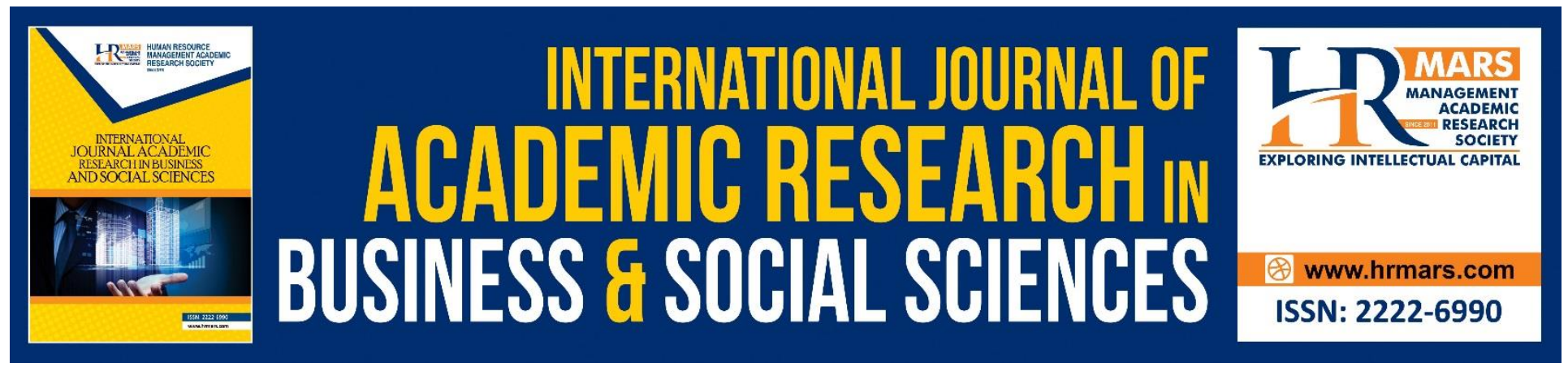

\title{
Extending the Heuristic Inquiry Research Process to Enable Improved Psycho-Spiritual Self-Care Choices Associated With Workplace Stress and Suffering
}

\section{Peter Devenish-Meares}

To Link this Article: http://dx.doi.org/10.6007/IJARBSS/v9-i6/6043

DOI: $10.6007 /$ IJARBSS/v9-i6/6043

Received: 20 April 2019, Revised: 17 May 2019, Accepted: 07 June 2019

Published Online: 28 June 2019

In-Text Citation:(Devenish-Meares, 2019)

To Cite this Article: Devenish-Meares, P. (2019). Extending the Heuristic Inquiry Research Process to Enable Improved Psycho-Spiritual Self-Care Choices Associated With Workplace Stress and Suffering. International Journal of Academic Research in Business and Social Sciences, 9(6), 858-883.

\section{Copyright: (c) 2019 The Author(s)}

Published by Human Resource Management Academic Research Society (www.hrmars.com)

This article is published under the Creative Commons Attribution (CC BY 4.0) license. Anyone may reproduce, distribute, translate and create derivative works of this article (for both commercial and non-commercial purposes), subject to full attribution to the original publication and authors. The full terms of this license may be seen at: http://creativecommons.org/licences/by/4.0/legalcode

$$
\text { Vol. 9, No. 6, 2019, Pg. } 858-883
$$

Full Terms \& Conditions of access and use can be found at http://hrmars.com/index.php/pages/detail/publication-ethics 


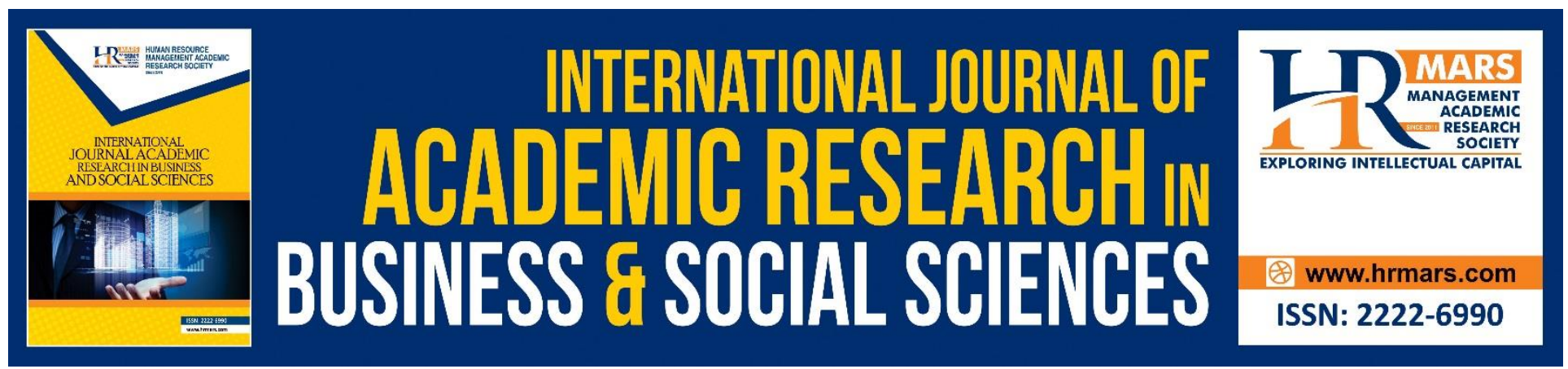

\title{
Extending the Heuristic Inquiry Research Process to Enable Improved Psycho-Spiritual Self-Care Choices Associated With Workplace Stress and Suffering
}

\author{
Peter Devenish-Meares \\ University of Notre Dame, Freemantle, Australia
}

\begin{abstract}
During workplace stress, feelings of failure and inadequacy can arise. Employee assistance and treatment practitioners not to mention the sufferer themselves often encounter the "heuristics of stress" where sufferers, because of well-established patterns can avoid self-care or engage in negative self-talk and self-judgment. This articles extends the heuristic inquiry process, for the first time, beyond use by researchers, to more directly inform a sufferer's self-kindly, psycho-spiritual self-care. It does this by synthesising and integrating selected scholarship on meaningful detachment, humility and self-compassion to intuitively challenge problematic inner patterns and stimulating self-compassion and inner reflection to bring about healing. In fact, subject to further confirmation, the intuitively-driven, heuristic inquiry process extends inter-disciplinary conceptualisations of self-care which enable the stressed and suffering, particularly as related to harsh self-judgments and blame to reflect on and discover meaning and transformative self-care options in and around the workplace. Finally, although more work is necessary, this paper offers an innovative and reflective approach to worker self-care.
\end{abstract}

Keywords: Workplace Stress, Self-Compassion, Humility, Detachment, Bricolage, Self-Care, Heuristics

\section{Introduction}

So often the stressed, anxious or suffering worker is working with outdated modalities of care, or avoiding self-care (Devenish-Meares, 2015a). They could possibly be so overwhelmed that reflecting on let alone making self-caring sense of their predicament seems impossible. At some level too, they may be seeking to make sense and heal but thought processes, patterns or issues get in the way, not the least of which are self-blame, lack of self-acceptance and an inability to access and enact helpful even transformative knowledge. 
In an earlier research methods paper, Moustakas' (1990) heuristic inquiry approach was examined as a way to encourage researchers to engage with the subjective and complex nature of workplace stress to stimulate self-care (Devenish-Meares, 2019). It appears that that this could assist psychospiritual self-care and sense-making and the explication of inner meanings and how to make sense of and transform workplace stress and suffering. This raised the focussed question: if the search "begins inside (the researcher's being and ultimately uncovers its direction and meaning through internal discovery", then why could the subject of the research use the process direct? (Djuraskovic \& Arthur, 2010, p. 1572).

Noting the potential use of the heuristic inquiry approach for researchers highlighted above, this paper takes this process further as a way to directly enable the sufferer or stressed to intuitively and transformatively reflect on their circumstances. It struck me over time that if an intuitive process opens the researcher up to compelling ways to reframe workplace stress then why not extend this practice for use by the subject directly. It is not intended to replace medical or psychological care.

As I begin I offer a personal note. Earlier papers helped me to come to awareness that I as researcher and practitioner am deeply and personally engaged, whatever the limits, bias and subjectivity in what I am studying. Heuristic inquiry helped me look closely at myself and what I was stuck in, from a workplace care perspective. Then rather than rejecting what arose it actually led me, as I neared the completion of my doctorate, to see that older forms of thinking, avoidance of self-care or the choice to do what has always been done didn't lead to insightful outcomes let alone transformation (Djuraskovic \& Arthur, 2010). Surely, I thought, the same avoidance patterns may be relevant to or occurring in the stressed and suffering worker.

Specifically, I often encounter what I call the "heuristics of stress" where people may first "default" to critical self-judgment. This is where the sufferer can (almost) automatically take a mental shortcut to negative self-talk or blame, because it a well-established inner pattern rather than actively engaging transformative and healing choices associated with self-care.

Pointedly, the heuristic inquiry process advanced by Moustakas (1990) "begins with the identification of a question that is deeply felt, a question that has an emotional effect on the researcher and cannot be ignored." (Kenny, 2012, p. 7). This appears remarkably similar to the inner state of avoiding or questioning and various affective responses that the sufferer is experiencing. It is as it were that both the researcher and the sufferer must "acknowledge these states (and) must live in and respond to the post-modern condition" (Kenny, 2012, p. 11).

The purpose then of this paper is to take heuristic inquiry further than being a research method and, in terms of workplace stress, explore its relevance to psycho-spiritual self-care and transformation. This will be based on real life vignettes where workers have lost hope, engage in negative self-talk and judgments, are suffering or have given up due to negative experiences and/or selfcondemnation. 
The heuristic inquiry process is relevant to personal issues such as stress and suffering because it is highly intuitive, focussed on enmeshment or fixation and paradoxically takes the person on a deeper reflection into a phenomenon, yet in a non-enmeshed way even as it expands choices and options for healing (Moustakas, 1990). Specifically, as Moustakas (1990) states, intuition connects "implicit knowledge inherent in the tacit and the explicit knowledge that is observable and describable" ( $p$. 23). This is as Moustakas (1990) says about the "internal capacity to make inferences and arrive at a knowledge of underlying structures or dynamics...intuition makes possible the perceiving of things as wholes" (p. 23). Such awakening, as a heuristic process is foundational for becoming aware at a deeper level as one moves to notice and modify older viewpoints or to develop new ones (Tejuosho, 2017).

\section{Workplace Stress: The Need for More Than One Response}

My work as a chaplain suggests that stress conditions can be related to or worsened by how one treats or cares for oneself, especially when one is isolated or away from work and possibly using selfjudgments or pejorative thinking. Underpinning this, workplace stress and suffering are often seen as reactions to work and less about psycho-spiritual meaning, despite the fact that stress can be associated with worsening self-perceptions (Moreno-Jimenez, Rodríguez-Munoz, Pastor, SanzVergel, \& Garrosa, 2009; Bakker \& Costa, 2014). Yet spirituality has something powerful to say in this space and this includes expressions of self-love (Schneiders, 2005; Charry, 2011).

Living one's values at work, being reflective, pastoral care of the anxious and suffering, adaptive wellness and supporting self-management are key areas of my research and practice (DevenishMeares, 2015a, 2016c). Moreover, psycho-spiritual self-care as a response to stress is relatively little examined in academia although recent findings have confirmed its efficacy in certain workplaces (Hotchkiss, 2018). Yet, such research also calls to mind inner meaning and spiritually-related themes to do with self-dialogue and sense-making, although frameworks to enact such choices are largely absent from workplace research and praxis (Weick, 1995). Where such themes are studied they most often focussed on performance and business outcomes (Aboul-Ela, 2017).

In terms of the dearth of research, my earlier works considered psycho-spiritual themes at work. It focussed on humility, detachment and self-compassion as distinct self-care choices or responses (Devenish-Meares, 2015a, 2016c, 2017). Then, it became clearer that not only were these useful in addressing self-blame and lack of self-acceptance but they needed further examination together and could form a self-choice framework. As a further impetus to this research, Burkhart (2014) indicated that self-care may be helpful in times of burnout and compassion fatigue amongst care workers (see also Skovholt, 2001). This is especially so when inner conversations are self-judging and blameful and lacking in inner hope (Cheavens, Feldman, Gum, Michael, \& Synder, 2006). Yet, as Hawkins and Shohet (2012) such self-talk could be about making meaningful sense of the "disturbance, distress and dis-ease" where they are right now (p. 21-22).

Moustakas's heuristic inquiry process approach helps move the researcher from the symptom reacting or feeling centre towards an intuitive self that can reflect, search and think in the tacit 
knowledge space. Underscoring this, Sela-Smith $(2002,55)$ says that "intuition is a valuable tool in assisting the researcher to notice when wholes do or do not exist, and providing information that exposes the need for a leap into the unknown". From this, how much too, do the stressed need to discover or intuit helpful, psycho-spiritual ways to make sense and transform painful affect?

In this, spirituality and positive psychology could challenge existing problematic or maladaptive thinking patterns and involve disciplines in new ways to support the stressed (Kennedy, 2012; Moustakas, 1990). From reflections, experience and reading it seems that people need support to return to deep or inner, self-kindly patterns that have been lost or buried under years of blame and self-recrimination (Isaksson, Tyssen, Hoffart, Sexton, Aasland, \& Gude, 2013, n. p; Montero-Marin, Prado-Abril, Piva Demarzo, Gascon, \& García-Campayo, 2014). After all, if people have been following the heuristics of self-blame, recrimination and self-judgments, how can they be encouraged to follow ideas related to positive self-reflection and self-care?

\section{Aim}

The aim of this paper is to conceptually explore how aspects of the intuitive, heuristic inquiry process, noting it is primarily designed for researchers, could be directly used by sufferers to reflect on their (inner) experiences intuitively and to make self-care choices. It is hoped that synthesising and integrating selected scholarship on self-kindness, improved self-acceptance and living well with incompleteness can intuitively challenge problematic inner patterns and stimulating self-compassion and inner reflection to bring about healing

I do note that this is a reflective paper and it will therefore have limitations and as such, later casestudy based research will be necessary to tests its efficacy. Specifically, the focus is psycho-spiritual self-care which is arguably a form of self-management although the term self-management in business research is often about performance. At whatever level, it means that one can become more self-aware and bring new perspectives to bear on what is occurring (Breevaart, Bakker, \& Demerouti, 2013; Thompson \& Waltz, 2008).

\section{Motivation: Using What Were Separate Themes in any Combination Necessary}

What motivates this research is that fact that based on chaplaincy experience and some, emerging psycho-spiritual research, there is an urgent need to explore inner sense-making and self-care choices (Hotchkiss, 2018). In this, the disaffected are encouraged to go on an intuitive journey of selfdiscovery. This is about exploring unknown or latent inner meanings in a movement towards selfcare and transformation (Anderson, 2004). Such a process recalls that one's pyscho-spiritual health could be assisted by self-inquiry. If this is so, then one must become a "perceiver of patterns" although this isn't necessarily a widely used skill and may need a supportive environment or reflective space in which to occur (Pinchbeck, 2006). What often may be lacking is a deliberate, intuitive process to give real effect to a bricolage approach. Then, over time for me, Moustakas' (1990) heuristic inquiry process emerged as an intuitive, personal method to incubate and illuminate what takes place interiorly so as to come to new self-caring awareness. 
This allows the self-care researcher to give honour to their own voice and the inner exploration of self-compassionate processes for the sufferer themselves (Devenish-Meares, 2019). This reflective process is emerging although it received interest from academics and practitioners, in what Anderson (2004) calls sympathetic.

The paper also seeks to inform the vital work of employee assistance programs (EAP) which can strengthen an employee's responses but does not necessarily consider psycho-spiritual issues. In fact, much more work could be done to develop the interdisciplinary connections between pastoral care, spirituality and EAP (Nimon, Philibert, \& Allen, 2008).

\section{A Focus on a New Method For Workplace Care Research and to Support the Stressed Themselves} In my research series, in response to workplace anxiety, stress and suffering, I am exploring multidisciplinary, reflective approaches to self-care. This is because people make sense of life in many ways and at least some of it at an inner or personal level (Weick, 1995). From this, one notes that methodological considerations as they relate to the human condition are always subject to critique, change and refinement to maintain usefulness, openness and adaptability.

Given the human condition and its subjectivity, I continually pursue adaptive and intuitive methodological approaches. What also needs to be borne in mind is that the subject matter, the sufferer, may not readily be able to locate an intuitive and/or creative space where they can engage in self-care and related non-judgmental and reflective, inner processes. Moustakas' (1990) heuristic inquiry process takes account of such needs and this forms the basis of how I proceeded. In this, I now briefly summarise how I came to this point in the psycho-spiritual research for the workplace. In summary, bricolage guides the research and heuristic inquiry process enacts it.

\section{Bricolage}

Bricolage is about seeking, co-opting and using knowledge, ideas and possibilities in a tapestry to inform research. It is not a means itself, rather it informs methods. Summarising its potential, Kellner (1999) indicated it provides focussed opportunities to build knowledge and create choices from disparate sources; arguably like what can occur in an interdisciplinary approach to stress. In fact, he says, and this uncannily mirrors how we can respond tenderly to workplace stress, "the more perspectives one can bring to their analysis and critique, the better grasp of the phenomena one will have and the better one will be at developing alternative readings and oppositional practices" (p. xii).

\section{Heuristic inquiry process}

"Heuristic inquiry is a qualitative research approach that represents a personal journey towards tacit knowing. It challenged me to use creativity, compassion, self-exploration, and introspection, and it provided me with the deep understanding of the meaning and the essence of the significant human experience" (Djuraskovic \& Arthur, 2010, p. 1585). 
The quote above recalls the deeply felt question that is all at once so personal, emotional and even in some even ill-defined ways, spiritual, that it propels the research (Kenny, 2012). Again, for workplace stress and anxiety, recalling my earlier research there is an imperative to engage with theory and inner knowledge in a simultaneous external and inner process of and for developing selfcare options. It is external because it will, recalling bricolage, co-opt from whatever theoretical source that is considered necessary. It is internal because it will be an inner reflection of what is occurring without getting overly enmeshed. In fact, this is where both theory and intuitive exploration assist in sense-making and transformative healing (Devenish-Meares, 2017).

The heuristic process as described by Kenny is summarised below. It is epitomised by the paradoxical processes of conscious and intuitive engagement, albeit of a non-intense and reflective nature. It also leads to immersion in and incubation of issues that may initially seem unrelated but could provide new self-care options.

\section{Moustakas' Heuristic Phases (as cited in Kenny, 2013, p, 8)}

Initial engagement: "The researcher's contact with the subject and question. Moustakas (1990) recognised that it is the autobiographical source of the question that generates the movement of the research as the researcher and the question seek clarity, understanding and integration.

Immersion: "The invitation, the experience or question to the researcher to stay fully with the experience of the phenomenon in whatever form it takes."

Incubation: "Recognition of the value for the researcher in retreating from intense and focused attention on the question or data to engage in activities that are unrelated to research".

Illumination: "Discoveries in science and philosophy come about when the investigator forgets the object of inquiry and engages in other activities. These moments of illumination show the experience brings with it a change in perception of the subject of the inquiry. The internal frame of reference that had previously been in place is often dramatically altered."

Explication: "Explication involves examining what has arisen in the process and coming to an understanding of what meaning it might hold"

Creative synthesis: "The many strands of experience and understanding that have emerged in the research are brought together to form a coherent whole."

Table 1: Moustakas' (1990) Heuristic phases 
Thinking heuristically, pre-existing inclinations towards negativity in a workplace context could be well-established mental shortcuts that arise almost without thinking (Kennedy, 2012). It may even be that one is unaware of self-care and sense-making options or even that one is not permitting a self-kindly self. Clearly the idea of choice is highly relevant, noting that sustained self-care can increase workplace life quality (Hotchkiss, 2018). Further, paying attention to life in a compassionate and intentional way is a healing activity (The Dalai Lama, 2001; Gilbert \& Woodyatt, 2017).

Each self-care choice or motif, though they may differ in approach, is focussed on improvements in well-being and alleviating psychological distress (Neff, 2003a). In fact, recent research found that self-compassion, as a form of positive psychology, is meaningful in stressful times and is related to a different kind of knowing, empathy and being open to others (Fuochi, Veneziana, \& Voci, 2018). This different and intuitive way of knowing in some ways summarises the heuristic inquiry process.

Such 'knowing' can be adapted for use in workplace self-care and especially in what Anderson, Braud and Valle (1996) term "compassionate knowing: loving and living through the experience" (p. 23). Arguably too, the proposed approach is an honouring of the perhaps silent, even quietened and emerging voice of the stressed and suffering who after all live daily with the experiences of stress, anxiety and suffering (Moustakas, 1990).

\section{Literature}

Recalling bricolage's search-driven openness to what is necessary and heuristic inquiry's adaption of knowledge and information from disparate sources, I now explore self-care themes that have continually resonated throughout the research series. These seemed, over time, to form a type of creative framework to guide responses and for the stressed to adapt and use.

In terms of self-blame, self-judgments and failure to self-love can be connected to or consequences of stress and suffering, again, self-compassion, humility and meaningful detachment arose asocative and healing-related, psycho-spiritual choices. I do not propose to examine the themes in detail here noting they have been comprehensively explored elsewhere. Then, discovery of the heuristic inquiry process, reinforced such choices as a reflective way to address stress and suffering. The themes are summarised below.

\begin{tabular}{|c|c|c|}
\hline Self-care theme & $\begin{array}{l}\text { Aspect(s) of workplace stress, } \\
\text { anxiety and suffering that the } \\
\text { themes may be responding to }\end{array}$ & $\begin{array}{l}\text { Representative } \\
\text { literature }\end{array}$ \\
\hline $\begin{array}{l}\text { Self-compassion } \\
\text { Being mindful, self-kindly }\end{array}$ & $\begin{array}{lcc}\text { Self-blame; } & \text { harsh } & \text { self- } \\
\text { judgments; } & \text { non } & \text { self- } \\
\text { acceptance; } & \text { failure to } & \text { love } \\
\text { oneself } & & \end{array}$ & Neff (2003a) \\
\hline $\begin{array}{l}\text { Humility - living with the } \\
\text { truth of what is; reality of } \\
\text { incompleteness; recognition } \\
\text { and respect for human } \\
\text { frailty }\end{array}$ & $\begin{array}{l}\text { Self-blame; harsh self- } \\
\text { judgments; non } \\
\text { acceptance; inability to accept } \\
\text { that things go awry; }\end{array}$ & $\begin{array}{l}\text { Rohr (2007, 2010); Funk } \\
(2005)\end{array}$ \\
\hline
\end{tabular}


INTERNATIONAL JOURNAL OF ACADEMIC RESEARCH IN BUSINESS AND SOCIAL SCIENCES Vol. 9, No. 6, June, 2019, E-ISSN: 2222-6990 @ 2019 HRMARS

\begin{tabular}{|l|l|l|}
\hline & $\begin{array}{l}\text { imperfection is the human } \\
\text { condition }\end{array}$ & \\
\hline $\begin{array}{l}\text { Meaningful (psycho- } \\
\text { spiritual) detachment }-\end{array}$ & $\begin{array}{l}\text { Separation from workplace yet } \\
\text { still ruminating painfully; }\end{array}$ & $\begin{array}{l}\text { Sonnentag and Fritz (2015); } \\
\text { Moreno-Jimenez, }\end{array}$ \\
tenderly "standing back" & refusing to access & Rodríguez-Munoz, Pastor, \\
from the symptoms etc. ; & $\begin{array}{l}\text { treatment(s); finding it difficult } \\
\text { less intense, inner } \\
\text { awareness }\end{array}$ & $\begin{array}{l}\text { Sanz-Vergel, and Garrosa } \\
\text { healing space }\end{array}$ \\
\hline
\end{tabular}

Table 2: self-care themes and aspects of workplace stress

Surprisingly, late in my doctoral research journey, the heuristic inquiry process emerged as a highly integrated way to reflect on and ultimately synthesise the themes above. This inspired a cycle of resting from and returning to the research. I discovered that one could build in deliberate pauses or spaces which allowed an illuminative process, and in particular usage of self-compassion, humility and meaningful detachment, to occur. Such a heuristic process is remarkably similar, to Rohr's standing further way motif. It is also directly related to the stressed and suffering and connected to the idea of a non-judgmental inner-witness who sees what is occurring from a respectful distance and in a self-kindly way. Again, from this, a key question arises; how does one make meaningful sense of, and care for self, in the presence of stressors or even (perceived) failure at work?

Similarly, Key and Kerr (2011) speak of heuristic separation from the intensity of the issue. If it can work for researchers then why not for the subject of the research? This form of focussing not only intentionally creates a space but also allows for new concepts and possibly even transformation to emerge, in our case, in the stressed or suffering one. Of note, recalling the space or detachment/separation idea, Key and Kerr (2011) say this form of focus is:

"where we completely come away from the question for a period of time. These smaller and larger openings to the unknown - like breathing in and out - are needed to allows something new to come into life. Relaxation and surrender unclench the mind's desperate grip on a problem, and allow space, mystery and freedom". (p. 63)

\section{Self-compassion}

Overall, using a bricolage approach, my earlier research extended self-compassion into the area of workplace stress and suffering (Neff, 2003a; Devenish-Meares, 2015b). It also relates in a practical way to Leigh's (1997) "compassionate self-talk" imperative. In that self-compassion activates mindfulness and self-lovability, it appears connected to discovery of Moustakas' tacit knowledge by bringing one's situation to self-kindly awareness. Yet again, it is the type of focus that is vital here; even a retreat from the often unhelpful intensity of painful rumination may create the conditions for self-kindness to be activated.

From the literature, self-compassion could be useful for chaplains and mental health practitioners; this is an area worthy of more research. One further outcome is that mental health interventions 
INTERNATIONAL JOURNAL OF ACADEMIC RESEARCH IN BUSINESS AND SOCIAL SCIENCES Vol. 9, No. 6, June, 2019, E-ISSN: 2222-6990 @ 2019 HRMARS

could be contextualised in self-compassion theory and in spirituality to assist workplace stress and suffering. It could possibly even inform aspects of PTSD care and support those who are unable to or do not choose to access care let alone recall that they are loveable.

Similarly, Rohr's (2010) self-love motif seems related to Moustakas' idea of unwavering attention and yet moves beyond this to enable or allow a more self-compassionate inner stance. Again, in terms of human dignity, one is worthy of self-kindness and gentle non-judgmental self-treatment (Charry, 2011). Rohr's (2007) idea is that we pay attention to what is, i.e. we don't avoid what is occurring. One re-considers ones affect and circumstances self-lovingly. As Rohr (2010) states, the whole self is loveable and worthy; in fact, "there is nothing to reject or avoid or be judged as unworthy; it has been forgiven much and loved much". (p. 185).

\section{Detachment}

Turning to detachment, research to date is almost always about "psychological detachment" from the proximity of work (Leigh, 1997; Sonnentag, 2012). However, noting enmeshed thinking and rumination as Meichenbaum (2007) said therapeutic responses based on stress education, skills acquisition and development of coping skills are needed to address consequences at both the organisational and the individual level. These include "maladaptive stress-engendering behaviors (e.g., avoidance, rumination and brooding, catastrophizing" (Meichenbaum, 2007, p. 7).

Recalling, the reflective, self-choice model and what Moustakas (1990) calls "incubation", this is about a less intense focus or no focus for a time as a way to create reflective spaces. It could, at least in part, addresses Moreno-Jimenez et al. (2009) question; what happens when "repetitive thoughts and feelings about past events are intrusive" (p. 360). Overall, noting the difficulties with psychological detachment alone, I discovered meaningful detachment, this time without problematic over-enmeshment and supported by self-compassion and humility (Devenish-Meares, 2017).

In this, Rohr's (2007) self-kindly "standing apart" motif is useful, being about observing oneself calmly and lovingly and is remarkably like the incubation phase of heuristics; i.e. retreating from an intense focus (Moustakas, 1990). Again, similar to heuristic inquiry, this different form of 'focus' is about noticing and standing further away from causation in a self-kindly, calm and more objective way (Rohr, 2007). Detachment still takes place but with a choice to actively lower intensity.

The heuristic process guides a different type of self-dialogue noting that self-talk is so often impaired or negative in times of stress and compassionate inner dialogue is missing (Bassett, 1995). At some level too, the sufferer may experience, know or come to know that they are ruminating, avoiding treatment, being self-critical, not coping, and not self-loving (Gilbert \& Woodyatt, 2017; MonteroMarin, Prado-Abril, Piva Demarzo, Gascon, \& García-Campayo, 2014).

As opposed to painful rumination, engagement is about a form of noticing, working to accept oneself and overcoming the negativity. This is also a key part of Neff's self-compassionate approach which speaks of the need to "know and forgive one's failings and foibles" (Neff, 2003a, p. 87). Notably too, 
self-compassion is not about avoidance of knowing but about paying attention in a tender way. It is also not unlike Rohr's (2007) inner-witness, detachment motif. In this, the sufferer is actively encouraged to use self-awareness and self-acceptance to know their circumstances but in a selfloving and self-allowing way that addresses even reduces negative self-judgments (Neff, 2003a).

\section{Humility}

Humility, which I examined elsewhere in more detail, is about explication because it is about the truth or reality as incomplete or unpalatable as it is (Funk, 2005; Devenish-Meares, 2016c). It points to the reality about issues not as we want them to be but rather how they really are (Rohr, 2007). Consequentially, guided by my heuristic hunches, inner experience and a seemingly perennial "dwelling on" the workplace phenomena it became clearer that such spirituality had much to offer. It is also noted that Charry's (2011) and Rohr's (2007) conceptualisations about spiritual choices and taking self-loving care of oneself appear remarkably similar to self-compassion (Devenish-Meares, 2016a, 2016b). Then there is the idea that if one detaches from work without inner support or is sent home and still ruminates painfully, problems may to arise if there no self-caring conceptualisation(s) (Devenish-Meares, 2017).

From this, with Moustakas' (1990) heuristic inquiry process of incubation and illumination I increasingly came to see the possibilities in terms of Rohr's (2007) spiritually-related ideas of humility and "standing further apart" from symptoms and saying "that's not all of me"; one is more than their painful affect.

\section{Discussion: Extending Heuristics: from Researcher to Subject}

Choices can involve drawing on seemly un-connected and previously un-compared sources and information (Douglas, 1986; Clemens, 1996). This is a focus on enhancing the researcher's and subject's self-awareness; in fact, the "experiencer's own internal frame of reference underpins the bricolage and is about heuristics" (Capps, 1990; Moustakas, 1990, p. 16).

Although positive psychology is well understood and widely used and appears related to certain spirituality, there are notable gaps in the literature that points to a need to distil interdisciplinary thinking to encourage personal self-care, stress responses and resilience approaches (Seligman \& Csikszentmihalyi, 2000; Bates, et al., 2010; Devenish-Meares, 2016a). How such an opportunity is seen by distressed individuals, made sense of, revisited in terms of symptoms in self-caring ways could not only influence coping processes they could also affect business outcomes and shape the type of care offered to people in adversity.

The sufferer and their carers could be encouraged to tenderly note patterns and where possible reframe them, change them or respond to them differently. This requires additional resources and information. It is also about engaging with deeply personal experience not just in terms of theory and concepts but compassionately living with and through what is occurring (Van Manen, 1990); again, paradoxically, in a less intense but inwardly-focussed way. This is where self-compassion, detachment and humility enable one to reflect on one's predicament in a less intense way, come in. 
Self-compassion argues for knowing and "forgiving one's failings and foibles and respecting oneself as a fully human and therefore, (as) a limited and imperfect being" (Neff, 2003b, p. 87). This recalls humility which Kriger and Hanson (1999) speak of, alongside compassion, as ways to heal in a workplace context. Again noting that heuristics is about norms or challenging norms albeit in complex human locales, the new rule of thumb presented here is a focus on self-loving and selfawareness oriented meaning making with a view to enhancing inner hope, healing and personal frameworks or conceptualisations of human dignity (Moustakas, 1990).

Moustakas' immersion process which is about non-judgmental self-exploration is similar to positive humility which is about seeing the truth about ourselves without judgment or self-blame. This is an opening up as Moustakas suggests to a natural process receptive to tacit and intuitive knowledge. It also recalls that one is engaged in self-inquiry and again must be a "perceiver of patterns"; the ones that prolong suffering and the ones that counter self-judgemental knowing (Pinchbeck, 2006).

All this has implications for accepting one's limitations provided we can know and understand them (Neff, 2009). This is as Coulehan (2010, p. 201) says about "honest self-awareness and reflection".

Certainly, such approaches can be complex, even circular and highly subjective and multi-dimensional processes. Yet for pastoral care, praxis circularity may be necessary as a sufferer explores and deepens their understanding and self-care choices. In summary, my approach examines and how to assist self-care in an improved understanding of self-compassion and certain aspects of humility and detachment at work and the choices related to these self-care themes.

Recalling Weick (1995), these choices take place at the level of meaningfully revisiting external occurrences and using inner-reflection oriented towards healing choices. This is an empowermentoriented approach where the client "becomes their own expert" (Corey, 2017, p. 482). Such actions appear remarkably similar to Neff's (2003a) conceptualisation of self-compassion about being aware, open to inner and person experience in a self-loving way. More specifically, this is a self-kindly approach to how one sees, accepts, judges and treats one's experiences holistically. It is not dissimilar to the comprehensive body, mind and spirit motifs of Bates et al., (2010) workplace fitness model, reframing experiences and considering personal choices.

All this has implications for recovery and healing. In fact, research indicates that individual choices around unfulfilled expectations and perfectionism are factors in stress and burnout (Swider \&

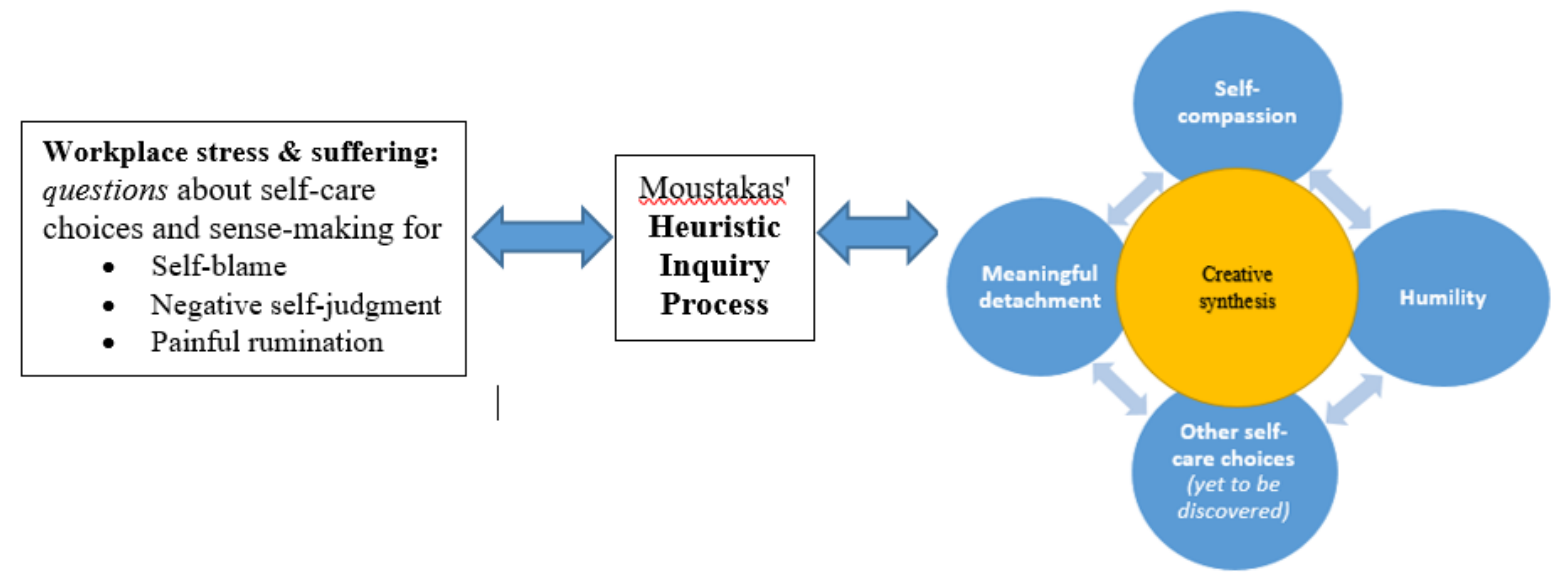


Zimmerman, 2010; Alarcon, 2011). Further, if one allows oneself to see new choices from whatever source then new self-care frameworks could emerge. From this, recalling bricolage and noting human subjectivity, it would appear beneficial to use the various themes around non-judgmental self-acceptance of experience to address the suffering occasioned by a sense of failure and imperfection whether these heuristic-related responses are objectively true or not (Neff, 2003a). Here, remarkable innovation could be set in motion because bricolage, as actioned in heuristic inquiry, enables the person to locate, dialogue with, seek new knowledge on and use whatever conceptualisations or ideas arise from whatever sources; with a focus on healing and inner transformation. As such, the heuristic exploration is shown below as recursive, non-linear and multidirectional. As shown in Figure two it is presented as a draft conceptual framework using selfcompassion, humility and meaningful detachment which each arose in earlier reflective research (Devenish-Meares, 2017).

\section{Figure 2: using heuristics to explore self-care choices}

\section{Workplace Application}

In terms of the literature and the brief discussion, the following section sets out succinct workplace examples. This is the re-conceptualisation of stress and enacting self-care, inner-transformation and sense-making (Weick, 1995). With this in mind, I explore self-compassion, humility and meaningful or psycho-spiritual detachment in terms of Moustakas' (1990) inner-dialogue, inquiry and illumination approach to guide the sufferer's self-caring choices. In this, I bear in mind that much lies within the inquirer that is not conscious: "the deep structure that contains the unique perceptions, feelings, intuitions, beliefs, and judgments housed in the internal frame of reference of a person that governs behavior and determines how we interpret experience" (Moustakas, 1990, p. 32).

\section{Initial Engagement: identify with the focus of the inquiry}

Representative workplace vignette (based on a real experience):

Mary knew something was wrong. Sure, the demands at work were never ending but so was the nagging unease and growing anxiety inside herself.

The starting point here is workplace-related stress symptoms which may include self-loathing and self-critique. These can become dominant (Murphy, 2003). I have seen regular occurrences at work where the sufferer gets stuck in over-identification and rumination (Sonnentag \& Fritz, 2015). In this, literature suggests the potential of an integrated approach to stress using self-caring awareness and self-acceptance (Neff, 2003a; Meichenbaum, 2007). Here it is about the stressed or sufferer locating and using new perspectives, choices and skills to do with stress, anxiety and suffering.

Practical workplace outcome: the worker is encouraged to reflect on the fact that they are not their pain and the symptoms that enmesh them; they are still loveable- drawing on Rohr (2007). Self-compassion theme (Neff, 2003a) offers specific and relevant action choices; 
INTERNATIONAL JOURNAL OF ACADEMIC RESEARCH IN BUSINESS AND SOCIAL SCIENCES

Vol. 9, No. 6, June, 2019, E-ISSN: 2222-6990 (C) 2019 HRMARS

"When I'm feeling down I try to approach my feelings with curiosity and openness"; "I'm tolerant of my own flaws and inadequacies. (p. 3)"

\section{Immersion}

The stressed worker is already immersed in the situation yet is this engagement always helpful and transformative? Immersion in Moustakas' (1990) process is about coming to tacit awareness. At work, it could be about how a worker has lost sight of themselves or judges themselves negatively.

Focusing on the stressful situation is not without challenges. It is as it were that the stressed person is laid bare which if it is to be navigated is going to need support and tenderness on the part of the therapist or carer. Certainly too, they may be physically away or separate from the workplace but still using established thought patterns; perhaps they judge themselves harshly, ruminate on their predicament and do not fully engage in treatment. This is particularly problematic when a person is removed from work and told not to think about it and yet they still engage in negative self-talk represented by harsh self-criticism (Arnos, 2017). Such negativity also calls to mind the risk of daily self-undermining which often has adverse implications for self-care let alone for recovery (Bakker \& Costa, 2014). This is why the choice to stand apart and notice is so crucial.

Humility is relevant here too because it supports non-judgmental self-exploration. This is where one simply (sic) notes stress or incompleteness without self-blame. One also calls to mind the complementary idea of self-compassion and not judging oneself harshly and seeing circumstances with self-loving eyes (Devenish-Meares, 2015a).

Practical workplace example: As a counterbalance to harsh self-criticisms, self-compassion and meaningful detachment offer a new way notice and converse in a self-kindly way with one's experiences. This is an extension of Moustakas' heuristics approach. It informs sensemaking and challenges existing self-critical rules. Using Neff's (2003b) self-compassionate questionnaire one "when something painful happens I try to take a balanced view of the situation (p. 232)".

\section{Incubation}

Representative workplace vignette (based on a real experience):

The experience of chronic stress left "John" feeling exhausted, with a burning sensation in his chest. Life seemed empty- there was no respite let alone joy. He goes "back and forth" in his head about happened: "What did I do or not do (right)?

Incubation is about a different focus, even no focus, for a time, and in the workplace context, by being supported to find spaces (perhaps meditation, breathing and diversionary activities) where the intensity is lowered. Pointedly, while much in suffering workers can be conscious there may be aspects taking place at the unconscious level. 
As highlighted in the example, choices, actions, failings and setbacks may become so consuming or overwhelming that one forgets, does not permit or possibly even blocks self-kindly choices, even though these could be helpful for the self. Due to performance expectations, negative judgments and (perceived) failure and related stress issues, one may not have the space, time or patience to engage with tacit knowledge which is: "the deep structure that contains the unique perceptions, feelings, intuitions, beliefs, and judgments housed in the internal frame of reference of a person that governs behavior (sic) and determines how we interpret experience" (Moustakas, 1990, p. 32).

Arguably, incubation can be accompanied by Rohr's (2007) meaningful separation (standing slightly further away) inner-witness motif which is remarkably similar to Moustakas' lower intensity idea. Here one comes to recognise the painful consequences of hard self-criticism and problematic selfjudgments. Then drawing from age-old spiritual praxis sees themes such as the innate person being inherently lovable (Rohr, 2007; Devenish-Meares, 2016b). This may or may not yet be a conscious choice so much as coming to an intuitive knowing that something is not as it should/could be.

Such a way of knowing offers an opportunity for a different, gentler form of reflection or not reflecting. In this, Neff (2003a) speaks of self-knowing. She says one must "know and forgive one's failings and foibles and respect oneself as a fully human and therefore, as a limited and imperfect being" (Neff, 2003a, p. 87).

Practical workplace example: In terms of a different way of reflecting, I suggest it is helpful to invite the stressed to detach or put aside the question(s) yet still sit with the question. Meaningful detachment is about a different kind of "observation" to reduce the power of the negative situation, even self-blame, so as to explore new, perhaps unexpected and previous unlooked-for options. Rohr's (2007) separation or standing away gently is like Rogers (1951) idea that, in this, boundaries can become relaxed and interior change can occur.

\section{Illumination}

Representative workplace vignette (based on a real experience):

No one can know my experience or its personal affects; I am alone and suffering. I can't face what keeps happening (in me). No one love me.

For the stressed this is where, albeit with support, they turn inwards. Moustakas $(1990$, p. 16) speaks of "turning inward to seek a deeper, more extended comprehension." When it comes to workplace suffering, this is a step where one reflects non-judgmentally that something or some event is painful, incomplete or on occasion, stress, anxiety and/or suffering. This may be real or perception based.

Illumination occurs because there has been an intentional retreat from the intensity of focus. For the stressed worker it may be accompanied by a friend or therapist who reminds them of their lovability. This process is about what Djuraskovic and Arthur (2010) term "illuminating themes from within. This phase requires a certain level of reflection but still allows for mysterious workings of the tacit knowledge" (Djuraskovic \& Arthur, 2010, p. 1578). 
INTERNATIONAL JOURNAL OF ACADEMIC RESEARCH IN BUSINESS AND SOCIAL SCIENCES

Vol. 9, No. 6, June, 2019, E-ISSN: 2222-6990 @ 2019 HRMARS

\section{Explication and Synthesis}

Representative workplace vignette (based on a real experience):

Stress was so overwhelming that I could not see any healing options or see myself in a place where relaxation, self-care or transformation were even possible. I have real fear about what the future generally and at work, holds.

Explication is where reflective space and lowering of intensity allow a fuller picture of the issues and new perspectives to emerge. This could include: I see no hope, I am very hard on myself due to perceived failures and never-ending performance expectations; I find it hard to step back selflovingly. Yet with the discernment of the dignity of the person and that self-care is available new options emerge. From the literature it is possible to conclude that ideas around meaningful detachment, self-compassion and self-loving emerge in the explication phase.

The final stage, critical synthesis may have started even during explication. This where an internal frame of reference emerges. In the context of suffering, a pre-existing internal frame of reference may have excluded self-kindly choices. Then, as I researched and reflected, this time taking the stressed's viewpoint, I saw commonalities between what is absent (this is often self-acceptance) and what could be self-compassion. It also made me go deep with my own experience of stress and workplace anxiety when performance demands are impossibly high. At some level, in affect or responses or avoidance the sufferer may exhibit or become aware that something needs attention. This reflects as Holmgren (1998) says that the person must "recover enough self-respect to recognize that she is a valuable human being in spite of what she has done" (p. 75). The unwavering attention aspect would appear to be augmented by Rohr's (2007) openness to "what is" motif. This is also about bringing loving kindness to bear on oneself (Devenish-Meares, 2016a, 2016b).

Here, I intentionally recall Rohr's (2010) self-love motif which helps address what is often missing at work; self-kindness and self-allowing. In term of Moustakas' idea of unwavering attention, Rohr assists one see that the self is valuable: "there is nothing to reject or "avoid or be judged as unworthy...(much) has been forgiven much and (one is) loved much". (Rohr, 2010, p. 185).

Practical workplace example: In terms of synthesis and use, a practical implication of Rohr's motif seems to be that it can move the worker beyond being told not to think; whereas one may still think (yet) in a non-judgmental acceptance and standing apart from pain to observe one's suffering in a self-kindly way (Rohr, 2007). Then, using listening and to borrow from Rogerian therapy, unconditional positive regard to encourage increased self-regard, the person is encouraged to see what is occurring at work against a broader perspective. Then there is the educative process of stress reactions which may reduce self-blame; i.e. addressing the self-dialogue with new information to counter the inner conversation and allow selfcompassion related choices to arise interiorly; e.g. "when I fail at something important to me I try to keep things in perspective" (Neff, 2003b, p. 224). 
Even from this brief paper, self-reflection and long term chaplaincy work with people seeking to develop a healing-oriented internal frame of reference, it appears to me that humility, self-awareness and self-compassion could benefit the sufferer in that it is about a reflective focus.

For stress and anxiety, this is about paying a form of attention yet in a self-compassionate way. Again, this is a form of meaning-laden inner attention where one notes the reality of suffering yet in a choice-laden movement that makes adjustments in awareness and focuses attention in self-loving ways. Here I recall Irvani (2007) who said "self-love, when authentic, indicates empathic understanding, awareness, compassion, and acceptance of one's self and others" ( $p, 9)$.

In this, one may come to realise how much one has forgotten about self-care or simply does not engage in self-care (Devenish-Meares, 2015b). Yet because of the less intense incubation phase, possibilities emerge from reading, review and reflection. Here the so-called forgetting, or not focusing on the suffering but more on self-acceptance and self-kindness, could lead to new insights (Kenny, 2012).

Reasons include the fact that self-love is about holding and valuing oneself, even at work where pressures abound. Of note, most treatment responses to workplace stress, suffering and burnout are short-term in nature and either clinically derived or performance-based. They do not necessarily engage in how the person really views or can inwardly reframe their predicament, activate healing and a desire to return to meaningful and productive work. This is despite some recent research which indicates that spirituality and positive psychology may be very useful and in particular, that emotional and spiritual intelligence are protective factors against workplace stress and anxiety.

Finally, such a focus could lead to meaningful inner shifts which is similar to (Meichenbaum's (2007) inoculation process. This is where analysis and skill development lead to "application and follow up" which specifically concentrates on "encouraging application of coping skills" (p. 43-47). Again, at some meaning-related inner level, improved self-care choices have to be brought to consciousness and allowed to take root in action!

Practical workplace example: a worker is supported to recognise that suffering or stress was all-consuming, rumination may be a typical response and self-love can be ignored. Through explication a different story or pattern can emerge; the person is not a failure and has worth and dignity and can make self-caring choices. Drawing specifically on self-compassion options (Neff, 2003b, p. 90-100) the focus can be "on the wholeness of one experience rather than solely on its (stressful) objects or parts". This can activate inner resources such as; what inner resources do I have? How do I recognise and address self-criticism; when things go awry, do I choose self-kindness versus self-judgment? (Neff, 2003b)

\section{Summary}

Even a brief illustration of Moustakas' (1990) heuristic process points to the benefits of integrating humility, self-compassion and a meaningful attachment to augment self-kindness and self-care. This interdisciplinary approach is about noticing and sense-making in a non-judgmental and self-loving 
way that reframes experience in terms of healing and self-kindness. In support of such augmentation, Rohr's (2007) inner witness idea may enable the suffering self to lessen cogitation and rumination, and rather stand apart from problematic experiences and pain. They do this by taking a calm, nonjudgmental and kindly $n$ view of their experience while in or near the troubling event or circumstance. These self-kindly choices could be regarded as a form of spiritual contemplation which help the affected to view the "unobserved" or false self, and by so doing, to gradually detach themselves from it. However, calm inner-detachment is not something that comes naturally in our culture: it has to be supported and practised.

Finally, this brief exploration extends bricolage-oriented and heuristically focussed research from theory to praxis. It advances the complex but potentially rich notion of drawing from as many sources as necessary. This includes those noting subjectivity, that are fragmented or incomplete. Arguably, bricolage and heuristics support and guide the researcher to explore multiple aspects of self-care in terms of workplace stress. It also notes that for the stressed, suffering and anxious one could engage in self-care choices in a movement using self-dialogue and focusing in new ways.

\section{Outcomes}

The research contributes to knowledge by exploring and extending conceptualisations of psychospiritual self-care for the stressed and suffering worker. It does this by offering a sense-making means to stand apart meaningfully in a self-caring way. In fact, from comparative analysis and in terms of Duymedjian and Rüling's (2010) bricolage-related knowing motif it seems that a choice framework could stimulate wellness oriented choices in response to suffering, failure and imperfection. This not only extends the extant research trajectory of self-compassion, self-love and humility into work but also helps its practical application and to "rehabilitate" applied humility and self-love as noteworthy spiritual values in the workplace recovery space. Recalling "creative synthesis" as Moustakas (1990) terms it, in this and later research there seems benefit in combining self-care themes in a form of innovative fusion or framework in what I have termed an inner movement; that is, a series of sensemaking and inner choices in response to suffering.

From this brief analysis, using heuristics to enable coping and sense-making we are drawing on established literature and practices associated with self-care and self-acceptance; almost a new set of helpful choices if not "guidelines" that are directed at enable kindly meaning-making. Such an approach could be termed self-allowing which combines self-compassion, self-love, humility and selfforgiveness themes. This is shown below and in terms of Duymedjian and Rüling's (2010) bricolagerelated concepts, self-compassion and meaningful detachment and positive humility are clearly action-oriented approaches to workplace suffering.

The re-conceptualisation seeks to synthesise and integrate choices related to coping, sense-making and meaning so as to integrate psychological and spiritual thought, develop values-based selfacceptance and increase understanding of perceptive, emotional, behavioural and inner-meaning functioning (Bates, et al., 2010). This preliminary framework offers treatment practitioners practical strategies to support the chronically stressed at work. From a synthesis of psycho-spiritual literature 
INTERNATIONAL JOURNAL OF ACADEMIC RESEARCH IN BUSINESS AND SOCIAL SCIENCES Vol. 9, No. 6, June, 2019, E-ISSN: 2222-6990 @ 2019 HRMARS

and workplace research it offers a holistic workplace fitness and care framework that develops protective factors in advance of stress; a term I call stress immunisation.

Another outcome is the tender and non-enmeshed illumination and reframing of one's stress-based predicament and the development of creative ways to deepen one's own self-care expertise and come to self-acceptance. As such, intuitive and personal choices that are affirmed in the heuristic inquiry process offer three practical outcomes and one potential, as yet unexplored, benefit:

1. An inner appreciation of and how the self can detach from self-blame by way of selfcompassionate choices, humility and intuitive-based self-awareness

2. Experiencing a sense of self-care i.e. they are not their judgments or so-called failures

3. Sense of stronger connection to oneself and a new framework to enact during times of stress

4. While the focus is self-care and meaningful transformation, an additional benefit could be workers returning to or persisting in work which may have personal, even economic, benefits.

\section{Limitations}

The study is theoretical in nature albeit through the experiential lens of the researcher as such it has methodological limitations. While the adopted approach, being based on personal immersion in and prolonged engagement for personal, subjective and subjective human studies, is affirmed by such as Anderson (2000, 2004) and Moustakas (1990), this does not confirm generalisability. A research design using established measures of stress and suffering contrasted against interventions or choices and specifically, Neff (2003a) self-compassion variables, Funk's humility approach and and Rohr's (2007) stand apart motif, would be of interest.

I also note that I focussed on psycho-spiritual self-care and then paid attention to self-kindly motifs that arguably address self-blame, self-judgment and non self-acceptance. Therefore, a limitation is that the operationalisation of such choices was not considered against or in conjunction with establish therapeutic or other psychological or psychiatric support mechanisms. In this too, noting my researcher experiences and interests I must declare a bias; as a Christian minister I am naturally going to see spirituality as holding a key place in workplace pastoral care. Yet, I also note as Schneiders (2005) says, that spirituality must also be open to modernity and new approaches. This is where each discipline informs the other and neither theology or psychology is preeminent.

Further there is risk that factors, other than the ones being included in the draft self-care framework are at play, that the "real answers" may lie elsewhere, or the data did not "really affirm" what was being proposed (Hagner \& Helm, 1993, p. 298). However, as far as is possible, noting this was a five (5) year study, the emerging framework would appear somewhat strengthened by:

- the preliminary albeit reflective and conceptual outcomes using a literature search

- detailed and thick descriptions

- sustained focus on methods; sympathetic resonance from researchers (Anderson, 2004) 
This is a personal discourse and the danger is that any researcher's experience can lead them to impose their own standpoints. A researcher can guard again this to some extent by a continual openness, supervision and constant review (Schneiders, 2005). Moreover, the researcher is, in essence, an interpretive bricoleur who "understands that research is an interactive process, shaped by his or her own personal history, biography, gender, social class, race and ethnicity, and by those of the people in the setting" (p. 6). This is certainly inherent in Moustakas' (1990) incubation, selfdialogue, illumination and explication process and for the researcher, at least, could be supported by a personal learning log and ongoing inner reflection.

There is also a perceived limitation in the research's "critical subjectivity". However, a constant review process was used. This is about the "quality of awareness in which we do not suppress our primary experience; nor do we allow ourselves to be swept away and overwhelmed by it; rather we raise it to consciousness and use it as part of the inquiry process" (Reason, 1988, p. 12). This is also augmented, as I discovered, if one remains open to peer-review, clinical supervision in terms of one's learning and reflective journals, and dialogue with psychological and medical practitioners.

Then, moreover, eight publications, three conference presentations and constant referral to practitioners and clinical supervisions produced what Anderson (2004) terms sympathetic resonance.

\section{Future Research}

Any heuristic inquiry is only going to explore what comes to consciousness or tacit awareness. The initial 'outcomes' albeit highly subjective in nature, are affirmed by what Anderson (2004) calls "sympathetic resonance" in and from various reader groups (academics, researchers and workplace care practitioners). Specifically, this is evidenced by more than ten paper which reference the themes that this research series has raised to consciousness.

However, there is much more to do. What immediately comes to mind is exploration of the initial, conceptual self-care framework through case study method and quantitative approaches; even a regression analysis may produce fruitful insights. Such an approach ought to include Neff's (2003b) self-compassion variables (self-kindness, common humanity, and mindfulness). These could be used as independent variables alongside humility and detachment measures and contrasted with stress.

The study is arguably the first to have used heuristic inquiry to strengthen approaches to self-care using self-compassion, combined with humility and meaningful detachment. A number of recommendations for future research follow.

- Extending heuristics: from researcher to subject. Qualitative and quantitative exploration will be necessary to explore if and how the heuristic inquiry process can be used sustainably by the stressed to explore and deepen their appreciation of self-care choices related to transformation including any self-critical "rules" that led to self-judgments and suffering.

- Research approaches to generalise the findings - using case study and quantitative approaches to extend the preliminary conceptual framework. 
- Self-forgiveness. This emerged late in the research as an additional, potential concept. This is not because any blame should be ascribed to the workplace stressed but rather because it is the perception of failure that may approximate self-blame. Drawing from the literature as to how can one forgive oneself, whether there is wrongdoing or not, may be useful. For example, in such literature there is material around the concept of one's positive self-view (Pargament, McCullough, \& Thoresen, 2000).

While potential next steps are myriad this study has nevertheless been a first practical step in considering psycho-spiritual approaches to self-care and sense-making. It is hoped that this research stimulates interest in psycho-spiritual self-care, both from a theoretical and praxis point of view and that future research will provide a clear picture of the scope and nature of various interventions.

\section{Conclusion}

The study, for the first time extended Moustakas (1990) heuristic inquiry approach for more direct use by stressed and suffering workers. It seems that the more self-caring support that people have and the more intuitive choices they can enact the more likely they could avoid negative selfjudgments and the prolongation of suffering, harsh self-talk and lack of self-love.

While not necessarily a linear approach the heuristic inquiry approach offers a step-by-step way to intuitively reflect on, make meaningful sense of and alleviate stress symptoms.

\section{Major findings}

- The heuristic inquiry process extends various, inter-disciplinary and intuitive conceptualisations of self-care choices. These enable the stressed and suffering worker, particularly as relate to harsh self-judgments and self-blame to reflect on, become more aware of and use helpful inner meaning connotations and transformative self-care options

- Arising from an intuitive and reflective approach, there is impetus for further exploration of positive psychological and applied spirituality themes which support a healing-centred, inner self-care narrative

- Subject to further examination, the heuristic inquiry process seems well suited for giving effect to self-care choices.

\section{Suggestions}

As this is an exploratory paper, future research is needed to examine, especially using case studies, in particular, the generalizability and validity of the posited approach. Noting Wilber's (1999, p, 43), inner-meaning experience, needs to be "repeatable, reproducible and confirmable" strongly suggests the need for much more qualitative and quantitative research. This should explore the efficacy of measures that relate to self-care choices as protective factors particularly in times of stress or anxiety.

It is suggested that to validate the conceptual framework for different workplace conditions (such as chronic stress, anxiety and PTSD) researchers will need to use multiple methods and seek 
ongoing input from workplace leaders, human resources specialists and mental health treatment practitioners. Moreover, to develop sound, replicable approaches to practical, employee self-care, it will necessary to comprehensively understand psycho-spiritual imperatives associated with work and better understand the personal issues and choices associated with what encourages or impedes self-care in times of chronic stress and even PTSD.

Overall, from this research there is the distinct possibility that intentional mental and self-care activities could enable workplace sense-making, healing and even a return to wellbeing (Black Dog Institute, 2017). While this research is necessarily focussed on individual care and choice factors, it is clear that stress care factors can be both intrapersonal and interpersonal. This should focus future research on resilience-type education to do with the psycho-social skills and inner meaning related reflection at work. It may also be well worthwhile to explore what blocks or allows self-care choices to come into frame.

Here I have only briefly explored workplace stress and suffering, as far as is possible, to do with positive psychology, meaning and spirituality. Notably too, self-forgiveness emerged very late in the process, noting how iterative and intuitive the inner journey is. It would appear to be an as yetunexplored, workplace-related healing option for the stressed that could be integrated into the emerging self-care framework.

\section{References}

Aboul-Ela, G. M. B. (2017). Reflections on workplace compassion and job performance. Journal of Human Values, 23(3), online. Retrieved from https://journals.sagepub.com/doi/abs/10.1177/0971685817713285?journalCode=jhva

Alarcon, G. M. (2011). A meta-analysis of burnout with job demands, resources, and attitudes. Journal of Vocational Behavior, 79, 549-562.

Anderson, R. (2000). Intuitive inquiry: Interpreting objective and subjective data. Revision, 22(4), 31-39.

Anderson, R. (2004). Intuitive Inquiry: an epistemology of the heart for scientific inquiry. The Humanistic Psychologist, 32, 307-341.

Anderson, R., Braud, W., \& Valle, R. (1996). Disciplined inquiry for transpersonal studies: Old and new approaches to research. Working Paper Number 1996-1. Palo Alto: William James Center for Consciousness Studies. Institute of Transpersonal Psychology.

Arnos, O. M. (2017). Perceived stress, self-compassion, and emotional variance in parents of children with communication disorders: A family approach to service delivery in speech-language pathology. Thesis, Illinois State University.

Bakker, A. B., \& Costa, P. (2014). Chronic job burnout and daily functioning: A theoretical analysis. Burnout Research, 1, 112-119.

Bassett, L. (1995). From panic to power. New York, NY: HarperCollins Publishers. 
INTERNATIONAL JOURNAL OF ACADEMIC RESEARCH IN BUSINESS AND SOCIAL SCIENCES Vol. 9, No. 6, June, 2019, E-ISSN: 2222-6990 @ 2019 HRMARS

Bates, M. J., Bowles, S., Hammermeister, J., Stokes, C., Pinder, E., Moore, M., Fritts, M., Vythilingam, M., Yosick, T., Rhodes, J., Myatt, C., Fautua, D., Westphal, R., Hammer, P., \& Burbelo, G. (2010). Psychological Fitness. Military Medicine, 175, 21-38.

Black Dog Institute. (2017). Workplace wellbeing. Black Dog Institute. Retrieved from www.blackdoginstitute.org.au

Breevaart, K., Bakker, A. B., \& Demerouti, E. (2013). Daily self-management and employee work engagement. Journal of Vocational Behavior, 84, 31-38.

Burkhart, J. (2014). An integral model of self-care for clinical psychology graduate students. . Journal of Integral Theory and Practice, 9(1), 55-73.

Capps, D. (1990). Reframing: A new method in pastoral care. Minneapolis, MN: Fortress Press.

Charry, E. T. (2011). Positive theology: An exploration in theological psychology and positive psychology. Journal of Psychology and Christianity, 30(4), 291.

Cheavens, J. S., Feldman, D. B., Gum, A., Michael, S. T., \& Synder, C. R. (2006). Hope therapy in a community sample: A pilot investigation. Social Indicators Research, 77, 71-78.

Clemens, E. S. (1996). Organizational form as frame: Collective identity and political strategy in the American Labor Movement, 1880-1920. In D. M. McAdam, Comparative perspectives on social movements: Political opportunities, mobilizing structures and cultural framings (pp. 205-226). Cambridge University Press.

Corey, G. (2017). Theory and practice of counseling and psychotherapy. London: Cengage.

Coulehan, J. (2010). On humility. Annals of Internal Medicine, 153, 200-201.

Devenish-Meares, P. (2015a). Call to compassionate self-care: introducing self-compassion into the workplace treatment process. Journal of Spirituality in Mental Health, 17(1), 75-87.

Devenish-Meares, P. (2015b). Chaplaincy in mental health treatment. Australian Defence Journal.

Devenish-Meares, P. (2016a). Moving through workplace suffering towards healing: a conversation between psychology - part 2. Australian Army Chaplaincy Journal, 65-95.

Devenish-Meares, P. (2016b). Moving through workplace suffering towards healing: a conversation between psychology and theology- Part 1. Australian Army Chaplaincy Journal, 33-59.

Devenish-Meares, P. (2016c). Humility as a force enhancer: developing leaders and supporting personal. Australian Defence Journal, 200, 68-78.

Devenish-Meares, P. (2017). A newer form of psycho-spiritual detachment to support those suffering at work. Journal of Spirituality in Mental Health, 28(2), 140-166.

Devenish-Meares, P. (2019). The 'tapestry' of bricolage: enhancing interdisciplinar approaches to psycho-spiritual workplace research. Methodological Innovations, in press. 1-14.

Djuraskovic, I., \& Arthur, N. (2010). Heuristic inquiry: A personal journey of acculturation and identity reconstruction. The Qualitative Report, 15(6), 1569-1593.

Douglas, M. (1986). How Institutions Think, 1st ed. Syracuse: Syracuse University.

Duymedjian, R., \& Rüling, C. C. (2010). Towards a foundation of bricolage in organization and management theory. Organization Studies, 31(2), 133-151.

Funk, M. (2005). Humility Matters: Toward Purity of Heart. Continuum.

Fuochi, G., Veneziana, C., \& Voci, A. (2018). Exploring the social side of self-compassion: Relations with empathy and outgroup attitudes. European Journal of Social Psychology, online. doi:10.1002/ejsp.2378 
INTERNATIONAL JOURNAL OF ACADEMIC RESEARCH IN BUSINESS AND SOCIAL SCIENCES Vol. 9, No. 6, June, 2019, E-ISSN: 2222-6990 @ 2019 HRMARS

Gilbert, P., \& Woodyatt, L. (2017). An evolutionary approach to shame-Based self-criticism, selfforgiveness, and compassion. In L. W. Woodyatt, Handbook of the Psychology of SelfForgiveness (pp. 29-41). New York: Springer.

Hagner, D., \& Helm, D. (1993). Qualitative methods in rehabiliation research. Thousand Oaks, CA: Sage.

Hawkins, P., \& Shohet, R. (2012) Supervision in the Helping Professions, 4th edn. Maidenhead: Open University Press.

Holmgren, M. R. (1998). Self-forgiveness and responsible moral agency. Journal of Value Inquiry, 32, 75-91.

Hotchkiss, J. T. (2018). Mindful self-care and secondary traumatic stress mediate a relationship between compassion satisfaction and burnout risk among hospice care professionals. American Journal of Hospice and Palliative Medicine, online.

Irvani, S. (2007). Authentic self-love as a healing phenomenon in systemic, relational psychotherapy. San Diego: Alliant International University.

Isaksson, K. E., Tyssen, R., Hoffart, A., Sexton, H., Aasland, O. G., \& Gude, T. (2013). A three-year cohort study of the relationship between coping, job stress and burnout after a counselling intervention for help-seeking physicians. BMC Public Health, 10. Retrieved from https://bmcpublichealth.biomedcentral.com/articles/10.1186/1471-2458-10-213

Kellner, D. (1999). Theorizing McDonaldization: A multiperspectivist approach. In B. Smart (Ed.), Resisting McDonaldization (pp. 186-206). London: Sage.

Kennedy, D. (2012). The relationship between parental stress, cognitive distortions, and child psychopathology. PhD Dissertation. Philadelphia College of Osteopathic Medicine.

Kenny, G. (2012). An introduction to Moustakas's heuristic method. Nurse Researcher. 19, 3, 6-11.

Key, D., \& Kerr, M. (2011). The Ouroboros (Part 2): Towards an intersubjective-heuristic method for ecopsychology research. European Journal of Ecopsychology, 2, 61-75.

Kriger, M. P., \& Hanson, B. J. (1999). A value-based paradigm for creating truly healthy organizations. Journal of Organizational Change Management, 12(4), 302 - 317.

Leigh, P. (1997). The new spirit at work. Training and Development, 51(3), 26-33

Meichenbaum, D. (2007). Stress incoluation training: a preventative and treatment approach. In R. L. P. M. Lehrer, Principles and Practice of Stress Management (3rd Edition). Guilford Press. Retrieved from http://www.brown.uk.com/anxiety/stress-inoculation.pdf

Montero-Marin, J., Prado-Abril, J., Piva Demarzo, M. M., Gascon, S., \& García-Campayo, J. (2014). Coping with stress and types of burnout: Explanatory power of different coping strategies. PLOS ONE, 9(2), online. Retrieved from http://journals.plos.org/plosone/article?id=10.1371/journal.pone.0089090

Moreno-Jimenez, B., Rodríguez-Munoz, A., Pastor, J. C., Sanz-Vergel, A. I., \& Garrosa, E. (2009). The moderating effects of psychological detachment and thoughts of revenge in workplace bullying. Personality and Individual Differences, 46(3), 359-364.

Moustakas, C. (1990). Heuristic research: Design, methodology, and applications. Newbury Park, CA: Sage Publications.

Murphy, J. G. (2003). Getting even: Forgiveness and its limits. New York: Oxford University Press. 
INTERNATIONAL JOURNAL OF ACADEMIC RESEARCH IN BUSINESS AND SOCIAL SCIENCES

Vol. 9, No. 6, June, 2019, E-ISSN: 2222-6990 @ 2019 HRMARS

Neff, K. (2003a). Self-Compassion: An Alternative Conceptualization of a Healthy Attitude Toward Oneself. Self and Identity, 2, 85-101.

Neff, K. D. (2003b). The Development and Validation of a Scale to Measure Self-Compassion. Self and Identity, 2, 223-250.

Neff, K. D. (2009). The Role of Self-Compassion in Development: A Healthier Way to Relate to Oneself. Human Development, 52, 212-214.

Nimon, K., Philibert, N., \& Allen, J. (2008) Corporate Chaplaincy Programs: An Exploratory Study Relates Corporate Chaplain Activities to Employee Assistance Programs, Journal of Management, Spirituality \& Religion, 5(3), 231-263, DOI: 10.1080/14766080809518706

Pargament, K. I., McCullough, M. E., \& Thoresen, C. E. (2000). The frontier of forgiveness: Seven directions for psychological study and practice. In K. P. M. MMcCullough, Forgiveness: Theory, research, and practice (pp. 299-319). New York: Guilford.

Pinchbeck, D. (2006). 2012: The Return of Quetzalcoatl. London: Jeremy P Tarcher.

Reason, P. (1988). Introduction. In P. Reason (ed), Human inquiry in action: Developments in new paradigm research. Newbury Park, CA: Sage.

Rogers, C. (1951). Client-centered therapy: Its current practice, implications and theory. London: Constable.

Rohr, R. (2007). Holding the tension: The Power of paradox [CD)]. Albuquerque, NM: Center for Action and Contemplation (CAC).

Rohr, R. (2010). The art of letting go: Living the wisdom of Saint Francis. (CD). Boulder, CO: Sounds True.

Schneiders, S. M. (2005). Approaches to the study of Christian spirituality. In A. Holder (ed), The Blackwell Companion to Christian Spirituality (pp. 15-34). Oxford: Blackwell Publishing.

Sela-Smith, S. (2002). Heuristic research: a review and critique of Moustakas's method. Journal of Humanistic Psychology, 42(3), 53-88.

Seligman, M., \& Csikszentmihalyi, M. (2000). Positive psychology: An introduction. American Psychologist, 55, 5-14.

Skovholt, T. M. (2001). The resilient practitioner: Burnout prevention and self-care strategies for counselors, therapists, teachers and health professionals. Needham Heights, MA: Allyn \& Bacon.

Sonnentag, S. (2012). Psychological detachment from work during leisure time: The benefits of mentally disengaging from work. Current Directions in Psychological Science, 21(2), 114-118. doi:10.1177/0963721411434979

Sonnentag, S., \& Fritz, C. (2015). Recovery from job stress: the stressor-detachment model as an integrative framework. Journal of Organizational Behavior, 36, s72-s103.

Swider, B. W., \& Zimmerman, R. D. (2010). Born to burnout: A meta-analytic path model of personality, job burnout, and work outcomes. Journal of Vocational Behavior, 76, 487-506.

Tejuosho, S. G. (2017). The Lived Experience of Being Raised by Single Alcohol-Dependent Father: $A$ qualitative heuristic study. Xlibris.

The Dalai Lama. (2001). An open heart: Practicing compassion in everyday life. Boston MA: Little Brown and Company. 
INTERNATIONAL JOURNAL OF ACADEMIC RESEARCH IN BUSINESS AND SOCIAL SCIENCES

Vol. 9, No. 6, June, 2019, E-ISSN: 2222-6990 (C) 2019 HRMARS

Thompson, B. L., \& Waltz, J. (2008). Self-compassion and PTSD symptom severity. Journal of Traumatic Stress, 21(6), 556-558.

Van Manen, M. (1990). Researching lived experience: Human science for an action sensitive pedagogy. Albany, NY: State University of New York Press.

Weick, K. (1995). Sensemaking in organizations. London: Sage.

Wilber, K. (1999). One Taste: The journals of Ken Wilber. Shambala. 